\title{
Estimasi Jejak Karbon dari Aktivitas Kampus Universitas Batanghari
}

\author{
Monik Kasman ${ }^{1}$, Anggrika Riyanti ${ }^{2 *}$, dan Novia Rezki Apriani ${ }^{3}$ \\ ${ }^{1,2,3}$ Program Studi Teknik Lingkungan, Fakultas Teknik, Universitas Batanghari \\ Jalan Slamet Riyadi, Kota Jambi \\ *correspondence email: anggrika.riyanti@unbari.ac.id
}

\begin{abstract}
Every individual or agency activity will generate greenhouse gas emissions which could be countable and expressed as equivalent to carbon dioxide. One of the activities that produce carbon emissions is activities carried out on the campus, one of which is Batanghari University. Batanghari University consists of 5 faculties, namely the Faculty of Teacher Training and Science, Faculty of Law, Faculty of Economics, Faculty of Engineering and Faculty of Agriculture with a total population of Batanghari University of 5,582 people including 5,278 students, 210 lecturers and 94 education staff. This study aims to analyze the amount of carbon emissions generated from activities of the Batanghari University and to compare the percentage of total carbon emissions produced from each scope. Calculation of carbon emissions using the method of The Greenhouse Gas Protocol (GHG Protocol), by dividing it into 3 scopes, including calculating the carbon footprint from transportation activities, emission form the used of gas, and emissions from electricity used and the used of paper. Carbon dioxide (CO $\left.{ }_{2}\right)$ emissions calculated by using the IPCC (International Panel On Climate Change) method. The results showed that the total carbon footprint produced at the Batanghari University for 6 months was 790.24 ton. $\mathrm{CO}_{2}$-eq. The distribution of emissions based on the scope as follows : scope 1 activity of electricity consumption was 162,705 ton. $\mathrm{CO}_{2}$-eq; scope 2 activities of using LPG was 0.609 ton.CO $\mathrm{O}_{2}$-eq; and the scope 3 transportation activities of lecturers, students and education staff was 625.91 ton. $\mathrm{CO}_{2}$-eq and paper usage activity are 1.0247 ton.CO ${ }_{2}-$ eq. The largest carbon footprint was generated from transportation activities at $79.2 \%$ and the smallest was the use of LPG at $0.07 \%$.
\end{abstract}

Keywords: Carbon footprint, $\mathrm{CO}_{2}$ emission, Global warming, Batanghari University

\section{Pendahuluan}

Pemanasan global merupakan peristiwa meningkatnya temperatur global dari tahun ke tahun dikarenakan efek gas rumah kaca yang disebabkan oleh meningkatnya emisi gas karbon dioksida $\left(\mathrm{CO}_{2}\right)$, metana $\left(\mathrm{CH}_{4}\right)$, dinitrogen oksida $\left(\mathrm{N}_{2} \mathrm{O}\right)$ dan $\mathrm{CFC}$ di atmosfer sehingga energi matahari terperangkap di atmosfer bumi. Pemerintah Indonesia berkomitmen akan melakukan penurunan emisi gas rumah kaca sebesar $26 \%$ dengan upaya sendiri namun dapat mencapai $41 \%$ dengan mendapatkan dukungan serta bantuan dari pihak internasional yang diperkirakan hingga tahun yang telah diungkapkan didalam kesepakatan Bali Action Plan pada The Conferences of Parties (COP) ke-13 United Nations Frameworks Convention on Climate Change (UNFCCC) dan hasil COP-15 di Copenhagen dan pada COP ke 16 di Cancun serta pada pertemuan di Pittsburg pada G-20

Setiap orang dalam beraktivitas sehari-hari yang menggunakan energi akan menghasilkan emisi karbon dioksida $\left(\mathrm{CO}_{2}\right)$, semakin banyak aktivitas manusia maka semakin banyak energi yang digunakan sehingga semakin besar pula jejak karbon yang dihasilkan (Rahayu, 2011). Kegiatan rumah tangga menyumbang emisi $\mathrm{CO}_{2}$ sebanyak $15 \%$, emisi karbon dioksida diperkirakan akan terus meningkat antara $0,3 \%$ hingga $2 \%$ per tahun, sehingga akan meningkatkan suhu bumi sekitar $1^{\circ} \mathrm{C}-5^{\circ} \mathrm{C}$ (Kodoatie dan Syarif, 2010). Selain itu penggunaan kendaraan bermotor akan mengemisikan berbagai jenis gas dan partikulat yang ikut menyumbang peningkatan emisi gas rumah kaca (Riyanti, dkk, 2018).

Jejak karbon merupakan total keseluruhan emisi gas rumah kaca yang disebabkan oleh aktivitas individu maupun suatu instansi yang dihitung dan dinyatakan setara dengan karbon dioksida (Cleanomic, 2019). Jejak karbon yang dimaksud adalah jejak karbon dari seluruh aktivitas manusia yang dapat menimbulkan emisi karbon. Salah satu aktivitas yang menghasilkan emisi karbon adalah segala kegiatan perkuliahan yang dilakukan di kampus salah satunya kampus Universitas Batanghari, kegiatan yang dilakukan di kampus berpengaruh terhadap banyaknya emisi karbon yang dihasilkan, sedikitnya jumlah pohon atau ruang terbuka hijau (RTH) yang berfungsi menyerap gas karbon dioksida $\left(\mathrm{CO}_{2}\right)$ juga berpengaruh dalam banyaknya karbon yang terlepas ke atmosfer (Aryo, 2018).

Universitas Batanghari merupakan perguruan tinggi swasta yang berlokasi di Kota Jambi yang berdiri sejak tahun 1985 dibina dan bernaung dibawah Yayasan Pendidikan Jambi. Universitas Batanghari (Unbari) terdiri dari 5 fakultas yaitu Fakultas Fakultas Keguruan dan Ilmu Pengetahuan, Fakultas Hukum, Fakultas Ekonomi, Fakultas Teknik dan Fakultas Pertanian yang terbagi menjadi 4 gedung yaitu gedung $\mathrm{A}, \mathrm{B}, \mathrm{C}$ dan gedung $\mathrm{D}$ serta gedung laboratoirum teknik. Total populasi Universitas Batanghari adalah 5.582 jiwa diantaranya 5.278 mahasiswa, 210 dosen dan 94 tenaga kependidikan (Unbari, 2019).

Aktivitas kampus Universitas Batanghari yang menghasilkan emisi karbon terbagi menjadi 2 antara lain aktivitas primer dan sekunder. Aktivitas primer yang menjadi penyebab emisi karbon antara lain aktivitas pembakaran bahan bakar fosil misalnya dari kegiatan transportasi dosen, mahasiswa dan tenaga kependidikan serta kegiatan memasak yang dilakukan di dapur setiap fakultas maupun kantin yang berada di dalam lingkungan kampus Universitas Batanghari. Aktivitas sekunder adalah aktivitas yang diemisikan secara tidak langsung misalnya penggunaan listrik untuk elektronika yang digunakan untuk semua kegiatan yang dilakukan di kampus seperti AC, proyektor, televisi, kipas angin dan lainlain.

Penelitian ini bertujuan untuk menganalisis jumlah emisi karbon yang dihasilkan dari aktivitas kampus Universitas Batanghari serta membandingkan persentase jumlah emisi karbon yang dihasilkan dari setiap lingkupnya. 


\section{Metode Penelitian}

\subsection{Lokasi dan Sampel Penelitian}

\section{a. Lokasi Penelitian}

Universitas Batanghari Jambi memilik 5 fakultas yang terbagi menjadi beberapa jurusan antara lain Fakultas Keguruan dan Ilmu Pendidikan, Fakultas Hukum, Fakultas Ekonomi, Fakultas Teknik, Fakultas Pertanian.

Universitas Batanghari memiliki berbagai aktivitas kampus yaitu aktivitas belajar-mengajar dan lainnya. Kegiatan tersebut didukung oleh fasilitas-fasilitas yang lengkap dan memadai, fasilitas yang disediakan oleh Universitas Batanghari diantaranya adalah 8 ruangan laboratorium, Gedung A-D yang terdiri dari 3-4 lantai serta fasilitas pendukung lainnya yang terdiri dari student training centre, club electronica, student guest house dan free hotspot. Gambaran tentang lokasi penelitian dapat dilihat pada Gambar 1 dan Gambar 2.

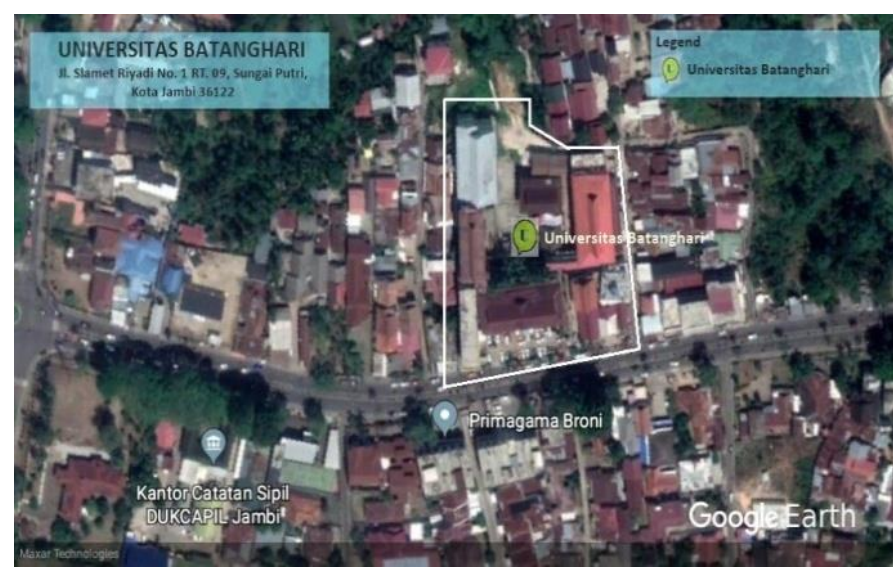

Gambar 1. Peta Wilayah Kampus Universitas Batanghari (Google Earth yang telah dimodifikasi, 2019)

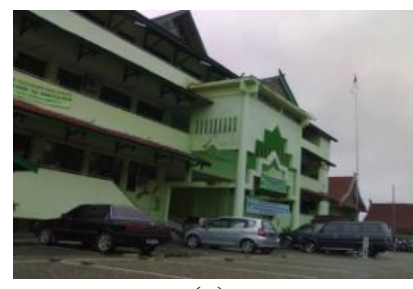

(a)

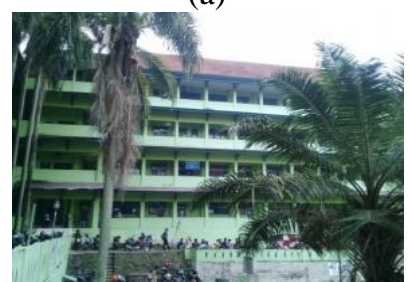

(c)

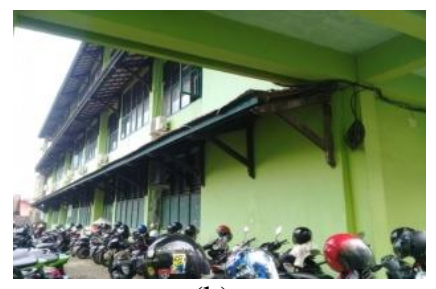

(b)

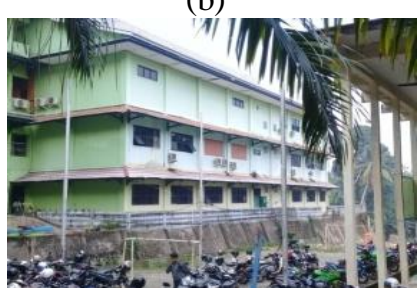

(d)
Gambar 2. Gedung Kampus Universitas Batanghari (a) Kondisi Gedung A (b) Kondisi Gedung B (c) Kondisi Gedung C (d) Kondisi Gedung D

\section{b. Populasi dan sampel penelitian}

Sampel penelitian yang digunakan adalah populasi Universitas Batanghari meliputi 5 fakultas dengan jumlah total populasi adalah 5.582 jiwa yang terdiri dari 5.278 mahasiswa, 210 dosen dan 94 tenaga kependidikan. Jumlah sampel penelitian yang digunakan sebagai penentu jumlah responden dihitung dengan menggunakan rumus slovin (menurut beberapa ahli derajat kesalahan yang dapat dipakai adalah $10 \%$ ) adalah sebagai berikut:

$n=\frac{N}{\left(1+\left(\mathrm{N} \alpha^{2}\right)\right.} A=\pi r^{2}$

Keterangan:

$\mathrm{n}=$ Jumlah sampel wilayah studi (orang)

$\mathrm{N} \quad=$ Jumlah populasi yang berada di area studi (orang)

$\propto \quad=$ Derajat kesalahan

Tabel 1. Jumlah Sampel

\begin{tabular}{ccc}
\hline Dosen & Mahasiswa & Tenaga Kependidikan \\
\hline 98 & 68 & 48 \\
\hline
\end{tabular}

\subsection{Perhitungan Jejak Karbon}

Penelitian ini merupakan penelitian kuantitatif. Pengumpulan data yang dilakukan di lingkungan kampus Universitas Batanghari, data terbagi menjadi data primer dan data sekunder, diperoleh dengan cara observasi, wawancara terbuka dan kuisioner.

Pengolahan data dari aktivitas primer dan sekunder untuk memperoleh nilai jejak karbon dari setiap lingkup dilakukan dengan metode GHG Protocol (The Greenhouse Gas Protocol) dan diperlukan metode perhitungan emisi yang handal dan diakui internasional, sampai saat ini IPCC (International Panel on Climate Change) adalah metode yang digunakan oleh seluruh negara yang meratifikasi UNFCCC (United Nations Framework Convention on Climate Change). Perhitunngan jejak karbon dibagi menjadi 3 lingkup, antara lain:

a. Lingkup 1 Aktivitas Pemakaian Listrik

Perhitungan jejak karbon pada lingkup aktivitas pemakaian listrik dihitung dengan rumus berikut:

Emisi = FE CO2 x Konsumsi Listrik

Keterangan:

$\mathrm{FE}=$ Faktor emisi $\left(0,774388897 \mathrm{Kg} . \mathrm{CO}_{2}-\mathrm{eq} / \mathrm{kWh}\right)$

Konsumsi Listrik $=$ Listrik yang digunakan $(\mathrm{kWh})$

\section{b. Lingkup 2 Aktivitas Penggunaan LPG}

Perhitungan jejak karbon pada lingkup aktivitas penggunaan LPG dapat dihitung dengan persamaan dibawah ini:

Emisi $=$ Konsumsi вв $x$ NK $_{\text {Bв }} \times$ FE $_{\text {Bв }}$

Keterangan:

$\mathrm{NK}=$ Nilai Kalor $(44,7 \mathrm{MJ} / \mathrm{l})$

$\mathrm{FE}=$ Faktor Emisi $\left(0,0631 \mathrm{~kg} \cdot \mathrm{CO}_{2}-\right.$ eq $\left./ \mathrm{Kg} . \mathrm{LPG}\right)$

\section{c. Lingkup 3 Aktivitas Transportasi Dosen, Mahasiswa dan Tenaga Kependidikan dan Pemakaian Kertas}

Pada aktivitas transportassi dosen, mahasiswa dan tenaga kependidikan, rumus yang digunakan sama dengan rumus yang digunakan pada aktivitas penggunaan LPG yaitu:

Emisi $=$ Konsumsi вв $\times$ NK

Keterangan:

NK = Nilai Kalor

$\mathrm{FE}=$ Faktor Emisi 
Tabel 2. NK dan FE Aktivitas Transportasi

\begin{tabular}{ccc}
\hline Bahan Bakar & Nilai Kalor $(\mathrm{MJ} / \mathrm{l})$ & FE CO2 \\
\hline Premium & 33 & 0,0693 \\
Pertalite & 33 & 0,0693 \\
Pertamax & 33 & 0,0693 \\
Solar & 36 & 0,0741 \\
\hline
\end{tabular}

Untuk menghitung emisi karbon dari aktivitas pemakaian kertas dapat dihitung dengan persamaan dibawah ini:

\section{Emisi = FE x Pemakaian Kertas}

Keterangan:

$\mathrm{FE}=$ Faktor Emisi Pemakaian Kertas (1,22 Kg.CO2-eq/Kg kertas)

\section{Hasil dan Pembahasan}

Jumlah total jejak karbon yang dihasilkan dari kegiatan-kegiatan yang dilakukan di kampus Universitas Batanghari yang telah dibagi menjadi 3 lingkup sebagai berikut:

\section{a. Lingkup 1 Aktivitas Pemakaian Listrik}

Pelayanan listrik pada kampus Universitas Batanghari meliputi kegiatan perkuliahan, sarana publik dan administrasi kampus. Total pemakaian listrik Universitas Batanghari selama 6 bulan terakhir yaitu bulan Juni hingga November adalah $210.107 \mathrm{kWh}$ yang terbagi menjadi 4 bargainser (meteran listrik) yaitu di laboratorium teknik, gedung A, gedung $\mathrm{B}$, gedung $\mathrm{C}$ dan gedung $\mathrm{D}$ dimana pada laboratorium teknik sebesar $2.852 \mathrm{kWh}$, gedung A sebesar $115.715 \mathrm{kWh}$, gedung B sebesar $45.367 \mathrm{kWh}$ dan pada gedung $\mathrm{C}$ dan D sebesar $46.173 \mathrm{kWh}$. Total jejak karbon dari aktivitas pemakaian listrik kampus Universitas Batanghari selama 6 bulan yaitu dari bulan Juni hingga November adalah 162,705 ton. $\mathrm{CO}_{2}$-eq/kWh.

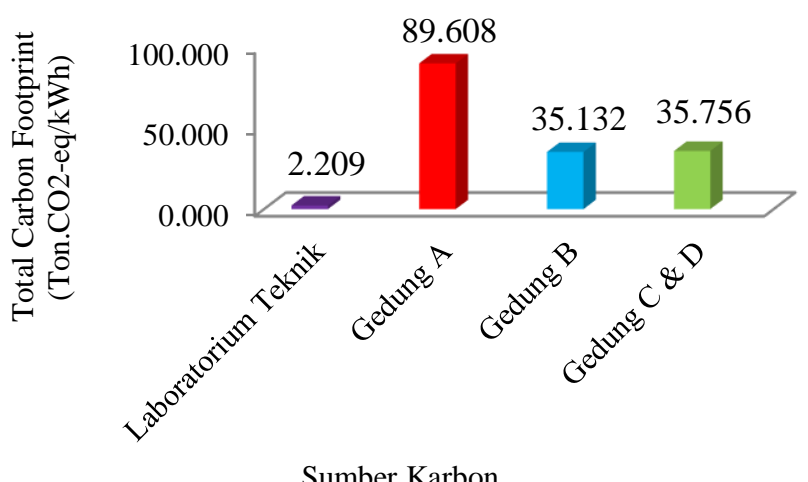

Gambar 3. Jejak Karbon Aktivitas Pemakaian Listrik

\section{b. Lingkup 2 Aktivitas Penggunaan LPG}

Penggunaan LPG dari aktivitas kampus bersumber dari aktivitas kantin yang berada didalam lingkungan kampus Universitas Batanghari dan dapur yang terdapat di fakultas Universitas Batanghari. Total penggunaan LPG di kampus Universitas Batanghari dalam 1 bulan adalah $36 \mathrm{Kg}$ yang bersumber dari dapur Fakultas Teknik dengan penggunaan 1 tabung $12 \mathrm{~kg}$ perbulan dan kantin yang berada didalam lingkungan kampus Universitas Batanghari sebanyak 8 tabung $3 \mathrm{~kg}$ dalam 1 bulan. Pada 4 fakultas lainnya tidak menggunakan kompor pada dapur fakultasnya sehingga tidak ada aktivitas yang menggunakan LPG. Jejak karbon yang dihasilkan dari aktivitas penggunaan LPG selama 6 bulan adalah 0,203 ton.CO2-eq yang kemudian diakumulasikan selama 6 bulan menjadi 0,609 ton.CO2-eq.

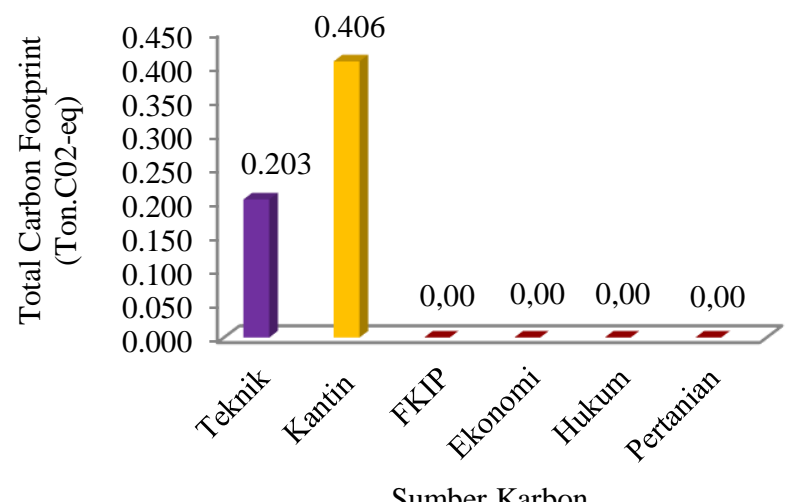

Gambar 4. Jejak Karbon Aktivitas Penggunaan LPG

\section{c. Lingkup 3 Aktivitas Transportasi Dosen, Mahasiswa dan Tenaga Kependidikan dan Pemakaian Kertas}

perhitungan dari analisis kuisioner dan perhitungan kendaraan secara manual selama 1 minggu dan didapat total jejak karbon yang dihasilkan dari aktivitas transportasi dosen, mahasiswa dan tenaga kependidikan yang telah diakumulasikan menjadi 6 bulan adalah sebesar 625,90 Ton. $\mathrm{CO}_{2}$-eq.

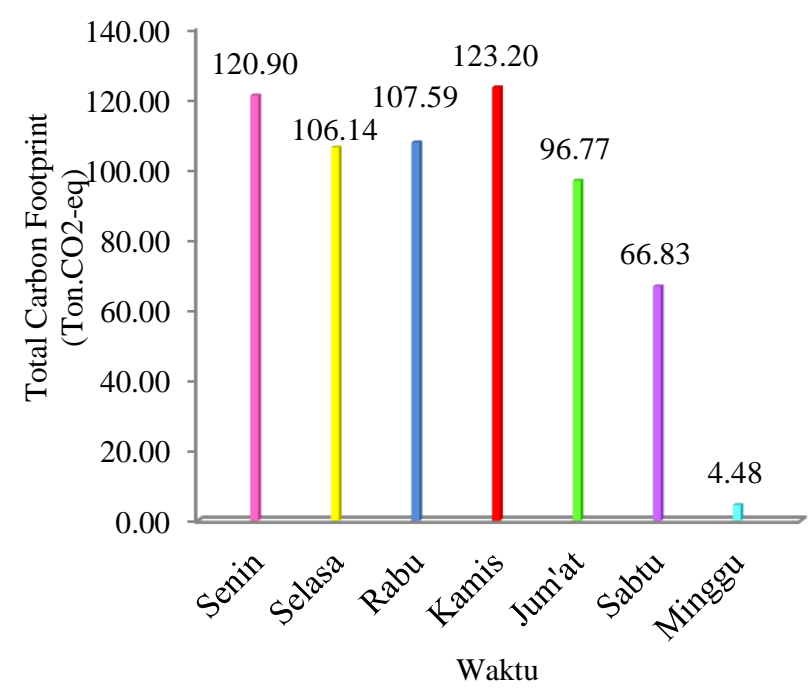

Gambar 5. Jejak Karbon Aktivitas Transportasi Dosen, Mahasiswa dan Tenaga Kependidikan

Total jejak karbon dari aktivitas pemakaian kertas selama 6 bulan (Juni-November) adalah 1,0247 Ton.CO $\mathrm{CO}_{2}$-eq. Adapun jumlah jejak karbon yang dihasilkan dari aktivitas pemakaian kertas pada Fakultas Teknik sebesar 0,0749 ton. $\mathrm{CO}_{2}$-eq, Fakultas FKIP sebesar 0,0501 ton. $\mathrm{CO}_{2}$-eq, 
Fakultas Hukum sebesar 0,0505 ton. $\mathrm{CO}_{2}$-eq, Fakultas Pertanian sebesar 0,0885 ton. $\mathrm{CO}_{2}$-eq, Fakultas Ekonomi sebesar 0,4398 ton. $\mathrm{CO}_{2}$-eq, BAUK sebesar 0,1315 ton. $\mathrm{CO}_{2}$-eq dan BAAK sebesar 0,1894 ton. $\mathrm{CO}_{2}$-eq.

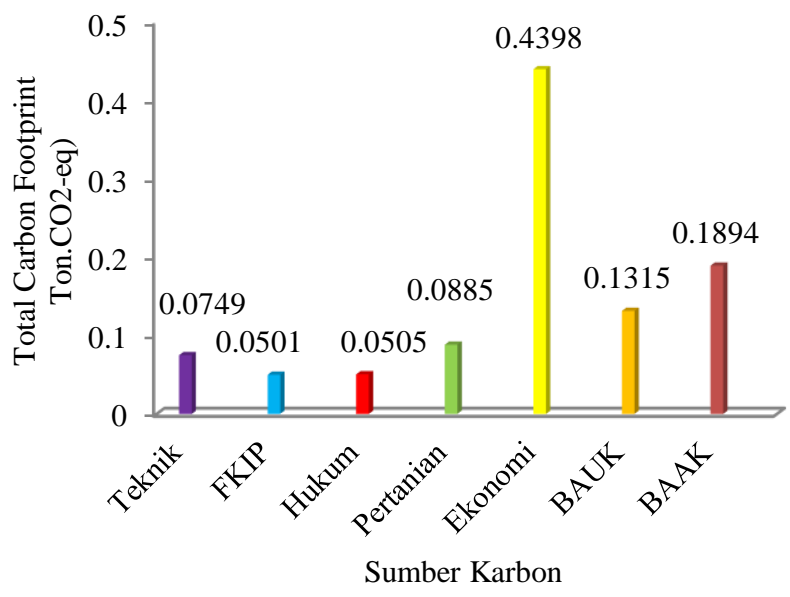

Gambar 6. Jejak Karbon Aktivitas Pemakaian Kertas

\section{d. Total Jejak Karbon 3 Lingkup}

Jejak karbon dari aktivitas di Universitas Batanghari pada tahun 2019 pada Lingkup 1 aktivitas pemakaian listrik menghasilkan jejak karbon sebesar 162,705 ton. $\mathrm{CO}_{2}$-eq/kWh. Lingkup 2 aktivitas penggunaan LPG menghasilkan carbon footprint selama 6 bulan sebesar 0,609 ton. $\mathrm{CO}_{2}$-eq. Lingkup 3 Aktivitas Transportasi Dosen, Mahasiswa dan Tenaga Kependidikan menghasilkan carbon footprint sebesar 625,91 ton. $\mathrm{CO}_{2}$-eq dan dari penggunaan kertas menghasilkan carbon footprint sebesar 1,0247 ton. $\mathrm{CO}_{2}$-eq.

Total carbon footprint yang dihasilkan dari aktivitas yang dilakukan di kampus Universitas Batanghari pada bulan Juni hingga November 2019 adalah sebesar 790,248 ton. $\mathrm{CO}_{2-}$ eq dan aktivitas yang terbesar menghasilkan carbon footprint adalah aktivitas transportasi dosen, mahasiswa dan tenaga kependidikan dengan persentase sebesar 79,20\% dan yang terkecil adalah aktivitas penggunaan LPG dengan persentase sebesar $0,0771 \%$.

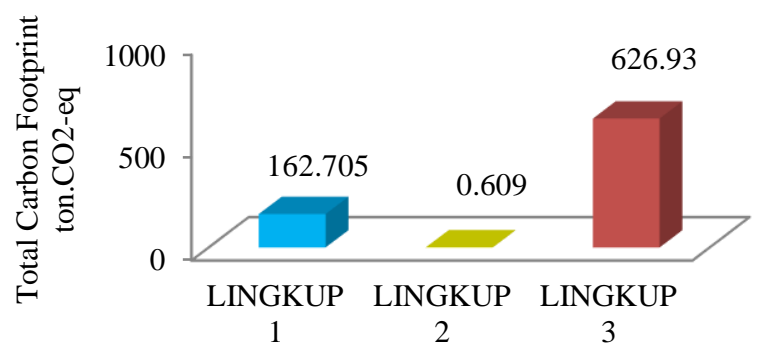

Sumber Karbon

Gambar 7. Jumlah Jejak karbon Universitas Batanghari Berdasarkan Lingkup

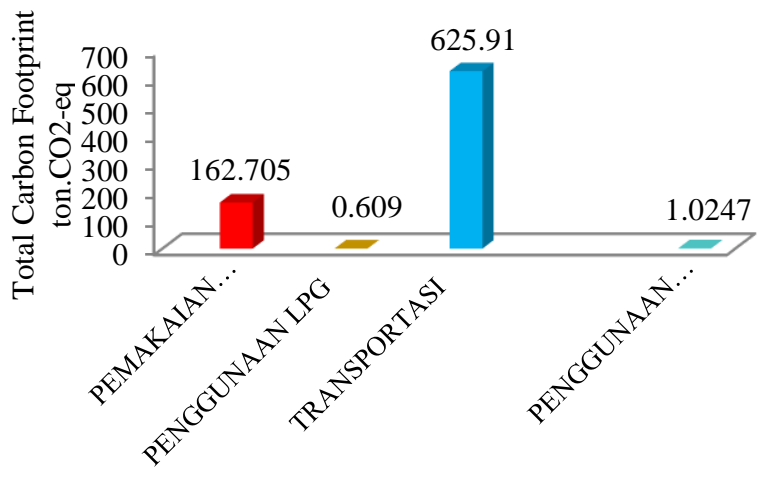

SUMBER

Gambar 8. Jumlah Jejak karbon Universitas Batanghari Berdasarkan Aktivitas

Persentase jejak karbon yang dihasilkan dari aktivitas di Kampus Universitas Batanghari yang paling besar adalah aktivitas transportasi dengan persentase sebesar 79,2\% dan yang paling kecil adalah aktivitas penggunaan LPG dengan persentase $0,07 \%$ (Gambar 9).

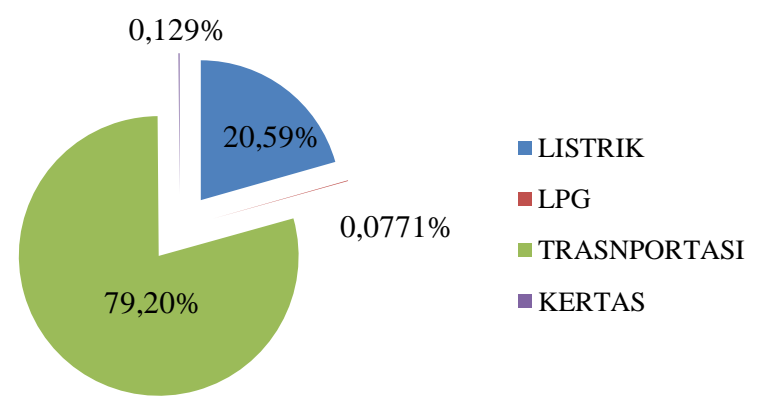

Gambar 9. Persentase Jejak karbon Universitas Batanghari Berdasarkan Aktivitas

\section{e. Minimalisasi Jejak Karbon}

Minimalisasi jejak karbon dari aktivitas di kampus Universitas Batanghari dilakukan dengan memberikan alternatif berupa membuat kebijakan dan merubah perilaku. Adapun beberapa cara untuk meminimalisasi jejak karbon antara lain:

1. Mematikan komputer pada saat tidak digunakan lebih dari 60 menit.

2. Mematikan AC jika tidak digunakan misalnya AC pada ruang kelas.

3. Mengganti aktivitas transportasi, untuk dosen, mahasiswa dan tenaga kependidikan yang memiliki jarak tempat tinggal ke kampus $>1 \mathrm{Km}$ disarankan untuk berjalan kaki dan yang memiliki jarak >1 KM untuk menggunakan kendaraan umum

4. Memilih bahan bakar kendaraan dengan oktan yang sesuai dengan mesin kendaraan agar lebih hemat energi dan terkendalinya emisi karbon.

5. Melakukan penghijauan seperti penanaman pohon serta tanaman-tanaman hias yang dapat membantu menyerap karbondioksida $\left(\mathrm{CO}_{2}\right)$. 


\section{Kesimpulan}

Dari penelitian ini, dapat disimpulkan sebagai berikut:

1. Total jejak karbon dari aktivitas di Universitas Batanghari pada bulan Juni hingga November 2019 sebesar 790,24 ton. $\mathrm{CO}_{2}$-eq yang dihitung dalam 3 lingkup sebagai berikut

a. Lingkup 1 aktivitas pemakaian listrik menghasilkan jejak karbon sebesar 162,705 ton. $\mathrm{CO}_{2}$-eq/kWh

b. Lingkup 2 aktivitas penggunaan LPG menghasilkan jejak karbon selama 6 bulan sebesar 0,609 ton. $\mathrm{CO}_{2}$-eq.

c. Lingkup 3 Aktivitas Transportasi Dosen, Mahasiswa dan Tenaga Kependidikan menghasilkan jejak karbon sebesar 625,91 ton. $\mathrm{CO}_{2}$-eq dan dari penggunaan kertas menghasilkan emisi karbon sebesar 1,0247 ton. $\mathrm{CO}_{2}$-eq

2. Aktivitas yang menghasilkan jejak karbon terbesar adalah aktivitas transportasi dosen, mahasiswa dan tenaga kependidikan dengan persentase sebesar 79,20\% dan yang terkecil adalah aktivitas penggunaan LPG dengan persentase sebesar $0,0771 \%$.

\section{Daftar Pustaka}

Artadi, F. (2013). Studi Jejak karbon dari Aktivitas

di Kampus Fakultas Teknik Universitas Indonesia. Depok: UI Press.

Ecometrica. (2011). Technical Paper Electricity -specific emission factor's and grid electricity.

EPA Victoria. (2013). Information Bulletin. Greenhouse Gas Emission Factors for Office Copy Paper.

IPCC. (2006). 2006 IPCC guidelines for national Greenhouse Gas Inventories. Volume II: Energy Japan: IGES

IPCC. (2007). Climate Change 2007: Mitigation, Contribution of Working Group III to the Fourth Assessment Report of the Intergovernmental Panel on Climate Change, $X X X$ pp. Cambridge, United Kingdom, and New York: Cambridge University Press.

Kementerian Lingkungan Hidup. (2012). Pedoman Penyelenggaraan Inventarisasi Gas Rumah Kaca Nasional. Buku II - Volume 1 Metodologi Perhitungan Tingkat Emisi Gas Rumah Kaca Kegiatan Pengadaan dan Penggunaan Energi.

Nurhayat. (2019). Prediksi Jejak Karbon Fakultas Sains dan Teknologi Kampus Pinang Masak Universitas Jambi. Jurnal Teknik Lingkungan

Peraturan Presiden Republik Indonesia Nomor 61 Tahun (2011) tentang Rencana Aksi Nasional Penurunan Gas Rumah Kaca.

Putri M, DA., dkk. (2017). Kajian Jejak Karbon Dari Aktivitas Kampus Fakultas Ekonomika Dan Bisnis Universitas Diponegoro. Jurnal Teknik Lingkungan, 6 (1).

Riyanti, A., dkk. (2018). Pengaruh Konsentrasi $\mathrm{NO}_{2}$ Udara Ambien pada Daerah Padat Kendaraan Terhadap Konsentrasi $\mathrm{NO}_{2}$ Udara Dalam Ruang (Studi Kasus di Kawasan Simpang Pulai Kota Jambi). Jurnal Daur Lingkungan, 1 (2) : 60-64.

Sagala, S. (2017). Kajian Jejak Karbon Dari Aktivitas Kampus Di Fakultas Teknik Universitas Negeri Semarang. Jurnal Teknik Lingkungan, 6 (1).

Universitas Batanghari. (2019). Sub Bagian Akademik dan Mahasiswa Universitas Batanghari.
WRI/WBCSD-World Resources Institute and World Business Council For Sustainable Development. (2004). The Greenhouse Of Protocol: a Corporate accounting and Reporting Standar. The Greenhouse Gas Protocol Initiative: USA and Switzerland.

WMO. (2014). Greenhouse Gas Bulletin: The State of Greenhouse in the Atmosphere Based on Global Observations through 2013. Geneva. No. 10. ISSN 2078-0796.

Wulandari, M.T. (2013). Kajian Emisi CO2 Berdasarkan Penggunaan Energi Rumah Tangga Sebagai Penyebab Pemanasan Global (Studi Kasus Perumahan Sebantengan, Gedang Asri, Susukan RW 07 Kab. Semarang). Prosiding Seminar Nasional Pengelolaan Sumberdaya Alam dan Lingkungan 2013, 1 (2) : 434440. 